\title{
Prognostic factors and the effect of radioiodine on patients with locally advanced differentiated thyroid cancer
}

\author{
Yao Yao ${ }^{1 \#}$, Shuai Cheng ${ }^{2 \#}$, Xinyu $\mathrm{Xu}^{3}$, Xinyuan $\mathrm{Chen}^{1}$, Wei Chen ${ }^{1}$, Yichun Qian ${ }^{1}$, Yuan Zhang ${ }^{1}$ \\ ${ }^{1}$ Department of Head and Neck Surgery, Jiangsu Cancer Hospital \& Jiangsu Institute of Cancer Research \& The Affiliated Cancer Hospital \\ of Nanjing Medical University, Nanjing, China; ${ }^{2}$ Department of Head and Neck Surgery, The Affiliated Cancer Hospital of Nanjing Medical \\ University \& Jiangsu Cancer Hospital \& Jiangsu Institute of Cancer Research, Nanjing, China; ${ }^{3}$ Department of Pathology, Jiangsu Cancer Hospital \\ \& Jiangsu Institute of Cancer Research \& The Affiliated Cancer Hospital of Nanjing Medical University, Nanjing, China \\ Contributions: (I) Conception and design: Y Zhang, Y Yao, S Cheng; (II) Administrative support: None; (III) Provision of study materials or patients: \\ None; (IV) Collection and assembly of data: All authors; (V) Data analysis and interpretation: All authors; (VI) Manuscript writing: All authors; (VII) \\ Final approval of manuscript: All authors. \\ "These authors contributed equally to this work. \\ Correspondence to: Yuan Zhang. Department of Head and Neck Surgery, Jiangsu Cancer Hospital \& Jiangsu Institute of Cancer Research \& The \\ Affiliated Cancer Hospital of Nanjing Medical University, Nanjing, China. Email: yzhang1963@163.com.
}

\begin{abstract}
Background: Locally advanced differentiated thyroid cancer (DTC) is rare. The optimal treatment remains controversial. This study was to investigate the natural history and prognostic factors of patients with locally advanced DTC and assess the effects of radioiodine therapy for locally advanced DTC.

Methods: A retrospective study was performed in 259 patients with locally advanced DTC. The clinicopathological features, prognostic factors and the effects of radioiodine therapy were evaluated using univariate and multivariate statistical analysis.

Results: Among the clinicopathological characteristics of locally advanced DTC, the patient's age (unfavourable $>55$ years), extent of primary tumour (more widely extrathyroidal extension showed a worse prognosis than others), tumor size, histopathological classifications and distant metastases were the significant prognostic factors. With regard to the effects of RAI on local invasive DTC, neither T3b nor T4 patients without distant metastases could benefit from performance of ${ }^{131} \mathrm{I}$ therapy for over survival and locoregional relapse-free survival.

Conclusions: In patients with locally advanced DTC, the independent prognostic factors were age, extent of extrathyroidal invasion, tumor size, histopathological classifications and distant metastases. Adjuvant postoperative RAI did not affect overall survival and locoregional control in patients with locally advanced DTC who had no distant metastasis disease. Given the results, we suggested radioiodine would not be applied for metastasis-free patients with locally advanced DTC postoperatively.
\end{abstract}

Keywords: Locally advanced differentiated thyroid cancer; clinicopathological features; prognosis; radioiodine therapy

Submitted Dec 02, 2018. Accepted for publication Jun 02, 2020.

doi: $10.21037 / \mathrm{atm}-18-1301$

View this article at: http://dx.doi.org/10.21037/atm-18-1301

\section{Introduction}

Well differentiated thyroid carcinoma (DTC) accounts for more than $80 \%$ of all thyroid malignancies with a 10 -year survival rate of over $95 \%(1,2)$. In most cases, the tumor is confined to the thyroid capsule. Extrathyroidal invasion, which occurs in $10 \%$ of cases, is associated with a worse prognosis for recurrence, distant metastases and the overall survival of DTC patient (3). Locally advanced 
diseases according to the 8th edition of the American Joint Committee on Cancer-TNM classification (2017), is defined as a tumour of any size with extrathyroidal extension. The surgical resection of involved structures, radioiodine therapy (RAI), and thyroid-stimulating hormone (TSH)suppressing therapy are the three main treatments used in the management of DTC patients. However, the optimal treatment modality in patients with locally advanced DTC remains controversial. In the present study, we investigated the natural history and prognostic factors of patients with locally advanced DTC and intended to assess the effects of radioiodine therapy for locally advanced DTC. We present the following article in accordance with the STROBE reporting checklist (available at http://dx.doi.org/10.21037/ atm-18-1301).

\section{Methods}

\section{Patients}

Between 2005 and 2015, 259 patients with a new diagnosis of locally advanced differentiated thyroid cancer were seen at the Department of Head and neck surgery, Jiangsu Cancer Hospital. Patients referred with recurrent disease were excluded. The patients were homogeneously evaluated in the preoperative work-up and operated on by the same surgical team. The trial was conducted in accordance with the Declaration of Helsinki (as revised in 2013). This study was approved by the Ethical Committee of Nanjing Medical University Affiliated Cancer Hospital (No. 2020032). Written informed consent was provided by all of the study participants.

\section{Variables}

Table 1 shows the age ( $<55$ or $\geq 55$ years), gender, sites of extrathyroidal extension, tumor size $(<1,1-4$ or $>4 \mathrm{~cm}$ ), $\mathrm{T}$ stage, $\mathrm{N}$ stage, $\mathrm{M}$ stage, diagnostic, therapeutic and histopathological variables and the outcome of the patient population. According to the Eighth Edition of AJCC Cancer Staging System, T3b category included 65 patients, while 194 patients belonged to T4 category. All patients received surgical treatment, consisting of non-total thyroidectomy, total thyroidectomy with involved structures and lymph node dissection. A subtotal thyroidectomy on $40(15.4 \%)$, a unilateral lobectomy on 91 (35.1\%), a total or near-total thyroidectomy was performed on 128 patients (49.4\%). En-bloc resection of invasive organ included the strap muscle, RLN, larynx, pharynx, trachea and esophagus with the goal of complete microscopic or macroscopic resection. Neck lymph node dissections were performed on 248 patients $(95.8 \%$ ) (central 83, central and lateral 165). Moreover, lymph nodes were found to be metastatic in 213 cases $(85.9 \%)$. After surgery, 78 patients $(30.1 \%)$ received ${ }^{131}$ I therapy, whereas 24 patients $(9.3 \%)$ were treated with external radiotherapy. L-Thyroxine at TSH-suppressing doses was then administered in all patients.

\section{Follow-up}

Patients were followed up at 3, 6 and 12 months after treatment, and then annually. All patients were followed up. The mean follow-up was 103 months (range, 6-172 months). Follow-up consisted of clinical examination, measurement of serum thyroglobulin and anti-thyroglobulin levels and highresolution neck ultrasonography. After follow-up, 39 patients (15.1\%) had died, 220 patients $(84.9 \%)$ were alive with or without disease. There were 47 patients (18.1\%) suffering from local-regional recurrence. Among them, thyroid bed recurrence was occurred in 12 patients (4.6\%), while lateral neck recurrence was found in 40 patients (15.4\%).

\section{Statistical analysis}

Patient data were analysed at the Statistical Department of Jiangsu Cancer Hospital. Univariate analysis was performed using the log-rank test for effect of ${ }^{131} \mathrm{I}$ therapy on overall survival rate and multivariate analysis using the Cox proportional hazard model. Overall survival probability was calculated using the Kaplan-Meier method. $\mathrm{P}<0.05$ was considered to be significant. The prognostic variables examined are shown in Table 1. All statistical procedures were performed using the statistical package SPSS for Windows, release 20.0 (SPSS Inc., Chicago, Illinois, USA).

\section{Results}

At univariate and multivariate statistical analysis (Table 2), with regard to overall survival, the significant prognostic variables were found to be the patient's age (unfavourable $>55$ years, HR, 0.227; 95\% CI, 0.109-0.475, P=0.000), extent of primary tumour (more widely extrathyroidal extension showed a worse prognosis than others, HR, 2.417; 95\% CI, 1.312-4.454, $\mathrm{P}=0.005)$, tumor size (HR, 2.033; 95\% CI, 1.161-3.558, $\mathrm{P}=0.013)$, histopathological 
Table 1 Characteristics and initial treatment of patients with locally advanced DTC ( $\mathrm{n}=259)$

\begin{tabular}{|c|c|c|}
\hline Patients' characteristics & No. & $(\%)$ \\
\hline \multicolumn{3}{|l|}{ Age (years) } \\
\hline$<55$ & 162 & 62.6 \\
\hline$\geq 55$ & 97 & 37.4 \\
\hline \multicolumn{3}{|l|}{ Gender } \\
\hline Male & 88 & 34.0 \\
\hline Female & 171 & 66.0 \\
\hline \multicolumn{3}{|l|}{ Histopathological classifications } \\
\hline Well differentiated thyroid cancer & 156 & 60.2 \\
\hline Classical papillary & 150 & 57.9 \\
\hline Follicular & 6 & 2.3 \\
\hline Aggressive variant DTC & 97 & 37.5 \\
\hline Tall cell variant & 93 & 35.9 \\
\hline Columnar cell variant & 2 & 0.7 \\
\hline Hobnail variants & 1 & 0.4 \\
\hline Sclerosing variant & 1 & 0.4 \\
\hline $\begin{array}{l}\text { DTC with poorly or anaplastic } \\
\text { differentiated component }\end{array}$ & 6 & 2.3 \\
\hline \multicolumn{3}{|l|}{ Sites of extrathyroidal extension } \\
\hline $\begin{array}{l}\text { Sternothyroid muscle or perithyroid soft } \\
\text { tissues }\end{array}$ & 65 & 25.1 \\
\hline Laryngeal nerve & 81 & 31.3 \\
\hline Trachea & 60 & 23.2 \\
\hline Larynx & 13 & 5.0 \\
\hline Esophagus & 51 & 19.7 \\
\hline Carotid vessels & 8 & 3.1 \\
\hline \multicolumn{3}{|l|}{ T stage } \\
\hline T3b & 65 & 25.1 \\
\hline $\mathrm{T} 4$ & 194 & 74.9 \\
\hline $\mathrm{T} 4 \mathrm{a}$ & 166 & 64.1 \\
\hline $\mathrm{T} 4 \mathrm{~b}$ & 28 & 10.8 \\
\hline \multicolumn{3}{|l|}{ Tumor size (cm) } \\
\hline$<1$ & 21 & 8.1 \\
\hline $1-4$ & 172 & 66.4 \\
\hline$>4$ & 66 & 25.5 \\
\hline \multicolumn{3}{|l|}{ Multifocality } \\
\hline Single & 171 & 66.0 \\
\hline Multifocal & 88 & 34.0 \\
\hline
\end{tabular}

Table 1 (continued)
Table 1 (continued)

\begin{tabular}{lrc}
\hline Patients' characteristics & No. & $(\%)$ \\
\hline Neck lymph node metastasis (N stage) & & \\
N0 & 46 & 17.8 \\
N1a & 59 & 22.8 \\
N1b & 154 & 59.4
\end{tabular}

Metastatic neck lymph node size $(\mathrm{cm})$

$\begin{array}{lrr}\text { No } & 46 & 17.8 \\ 1-3 & 172 & 66.4 \\ >3 & 41 & 15.8\end{array}$

Distant metastasis at presentation (M stage)

MO

$239 \quad 92.3$

M1

Resection margins

Ro

$187 \quad 72.2$

R1

$69 \quad 26.6$

R2

Thyroid surgery

Total/near total thyroidectomy $\quad 128$

Subtotal thyroidectomy

$40 \quad 15.4$

Lobectomy (unilateral thyroidectomy)

Lymph node surgery

$\begin{array}{lrr}\text { None } & 11 & 4.2 \\ \text { Central compartmental dissection } & 248 & 95.8 \\ \begin{array}{l}\text { Unilateral selective/radical neck } \\ \text { dissection }\end{array} & 115 & 44.4 \\ \begin{array}{l}\text { Bilateral selective/radical neck } \\ \text { dissection }\end{array} & 50 & 19.3\end{array}$

RAI

$\begin{array}{lll}\text { No } & 181 & 69.9\end{array}$

$\begin{array}{lll}\text { Yes } & 78 & 30.1\end{array}$

RT (EXT)

$\begin{array}{lll}\text { No } & 235 & 90.7\end{array}$

$\begin{array}{lll}\text { Yes } & 24 & 9.3\end{array}$

Summary of RAI and RT treatment (treatment modality)

\begin{tabular}{lrr} 
RAl alone & 67 & 25.9 \\
RT alone & 13 & 5.0 \\
Both RAI and RT & 11 & 4.2 \\
No RAI nor RT & 168 & 64.9 \\
\hline
\end{tabular}

DTC, differentiated thyroid carcinoma; RAI, radioiodine therapy. 
Table 2 Univariate and multivariate analysis of prognostic factors for overall survival in 259 patients with locally advanced DTC

\begin{tabular}{|c|c|c|c|c|c|c|}
\hline Variables & \multicolumn{3}{|c|}{ Univariate analysis } & \multicolumn{3}{|c|}{ Multivariate analysis } \\
\hline Gender (male:female) & 0.409 & $0.218-0.767$ & 0.005 & 0.595 & $0.304-1.166$ & 0.131 \\
\hline Age (yrs) $(\geq 55:<55)$ & 0.168 & $0.082-0.345$ & 0.000 & 0.227 & $0.109-0.475$ & 0.000 \\
\hline T stage (T3b:T4a:T4b) & 3.042 & $1.722-5.223$ & 0.000 & 2.417 & $1.312-4.454$ & 0.005 \\
\hline Multifocality (single:multifocal) & 0.684 & $0.333-1.403$ & 0.300 & - & - & - \\
\hline $\begin{array}{l}\text { Metastatic neck lymph node size }(\mathrm{cm}) \\
(\mathrm{N} 0: 1-3:>3)\end{array}$ & 2.054 & $1.186-3.557$ & 0.010 & 1.402 & $0.646-3.045$ & 0.055 \\
\hline N stage (N0:N1a:N1b) & 1.450 & $0.903-2.328$ & 0.124 & - & - & - \\
\hline
\end{tabular}

DTC, differentiated thyroid carcinoma.

classifications (the poorer the differentiation, the worse the prognosis, HR, 8.111; 95\% CI, 4.106-16.021, $\mathrm{P}=0.000$ ) and distant metastases (HR, 3.286; 95\% CI, 1.332-8.107, $\mathrm{P}=0.010)$. Figure 1 showed the overall survival curves for independently statistically significant prognostic factors. With regard to the effect of RAI on local invasive DTC, univariate analysis showed neither T3b nor T4 patients without distant metastases could benefit from performance of ${ }^{131} \mathrm{I}$ therapy for over survival and locoregional relapse-free survival. Figure 2 showed overall survival and local regional relapse-free survival curves for RAI applied to T4 patients without distant metastases. In T4 stage patients who had no distant metastasis disease without RT, the 10-year overall survival rates were not significantly different statistically between the two groups at $82.7 \%$ for the no-RAI group and $78.6 \%$ for the RAI group ( $\mathrm{P}=0.355)$. The locoregional control rates at 10 years were not significantly different (RAI $74.8 \%$ and no RAI $73.5 \% ; \mathrm{P}=0.666$ ).

\section{Discussion}

In general, DTC is characterized by a good prognosis after standard treatment. However, local tumor invasion may lead to high morbidity and mortality. Tumor invading to the adjacent tissues is considered as the most important unfavourable prognostic factor for local recurrence and distant metastases during follow-up (4-6). Therefore, an extensive surgical approach is recommended. On the contrary, limited operation for locally invasive DTC combined of surgery with ${ }^{131} \mathrm{I}$ therapy and/or external radiotherapy is recommended in attempt to avoid higher morbidity and mortality. In our experience, successful surgical management was achieved by resection of the tracheal rings, pharyngeal and esophageal mucosa and laryngectomy. It offers the patient a favourable outcome, in terms of overall survival. The 10 -year overall survival rate was $81.5 \%$. The statistical analysis performed on our data in Table 2 showed that the patient's age, extent of extrathyroidal invasion, tumor size, histopathological classifications, and distant metastases were the independent prognostic factors for overall survival.

Radioiodine (RAI) has been applied in the postsurgical treatment of DTC for years (7). Considering the side effects of radioiodine therapy for thyroid carcinoma such as carcinogenesis, lung fibrosis, and anemia etc, the role of RAI in locally advanced DTC, however, is matter of debate (8-12). In our data, in T4 stage patients who had no distant metastasis disease without RT, the 10 year-overall survival rates were not significantly different statistically between the two groups at $82.7 \%$ for the no-RAI group and $78.6 \%$ for the RAI group $(\mathrm{P}=0.355)$. The locoregional control rates at 10 years weren't significantly different (RAI $74.8 \%$ and 

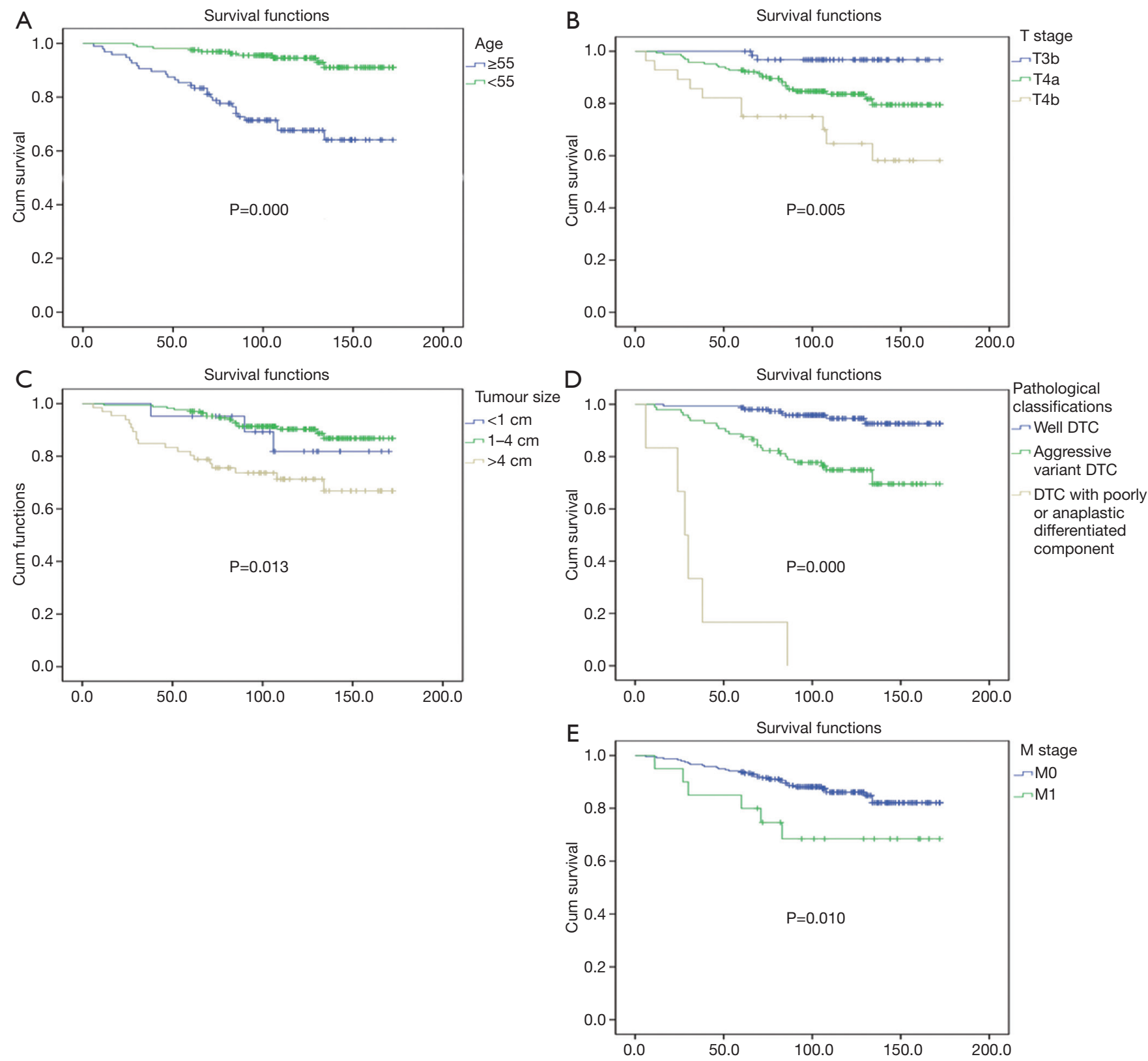

Figure 1 Comparisons are shown of overall survival (OS) curves for independently statistically significant prognostic factors: age at diagnosis (A), tumor stage (B), tumor size (C), histopathological classifications (D) and distant metastasis at presentation $(\mathrm{E})(\mathrm{P}<0.05)$.

no RAI 73.5\%; $\mathrm{P}=0.666)$. The data from our series showed that ${ }^{131} \mathrm{I}$ therapy did not seem to play a beneficial role, both with regard to the overall survival and local-regional control.

This study is a retrospective single-center study. Further prospective multi-center studies are required to avoid the bias.
In conclusion, on the result of our data in the present study, in patients with locally advanced DTC, the independent prognostic factors were age, extent of extrathyroidal invasion, tumor size, histopathological classifications and distant metastases. Adjuvant postoperative RAI did not affect overall survival and locoregional control in patients with locally advanced 

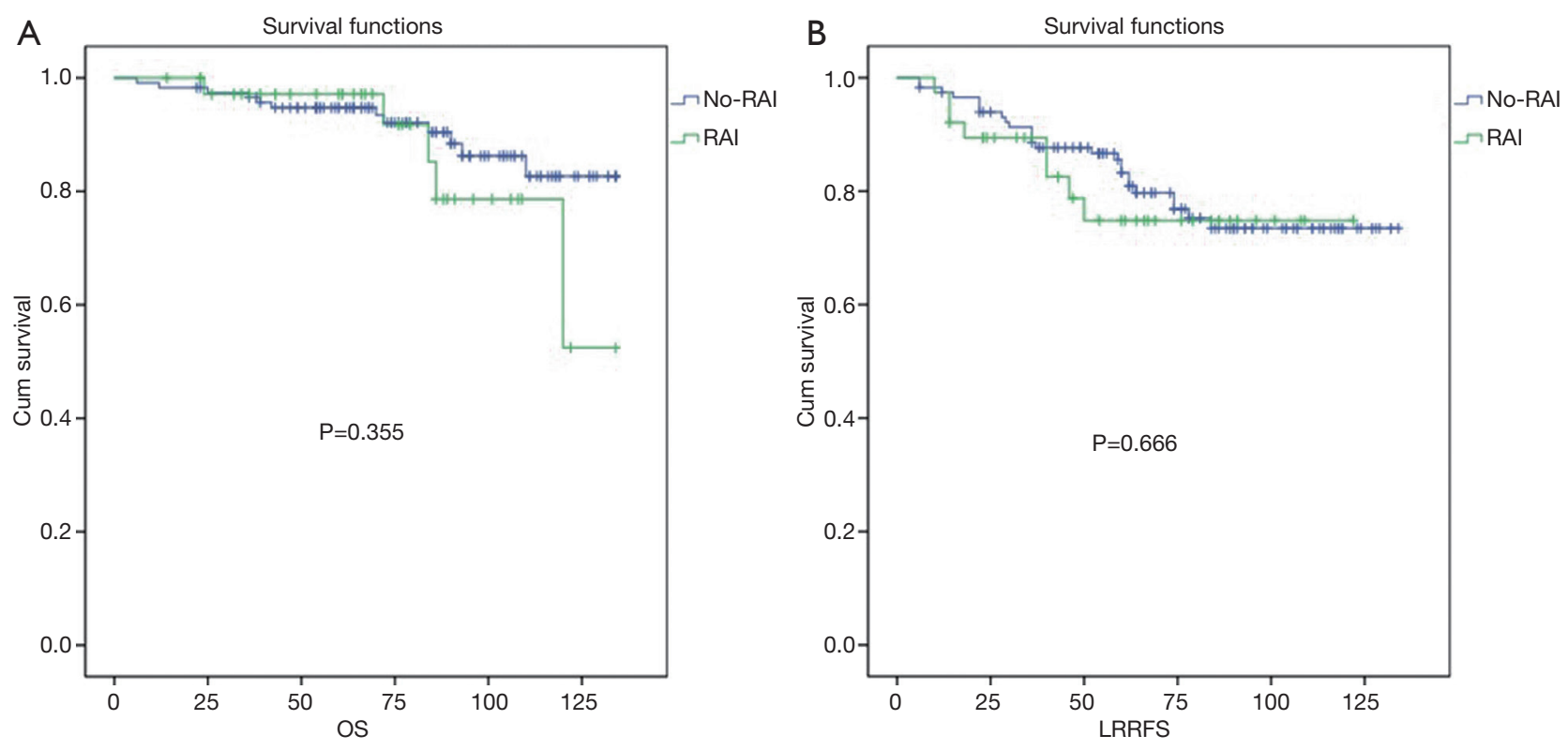

Figure 2 Comparisons are shown of overall survival (OS) (A) and local-regional relapse-free survival (LRRFS) (B) curves for T4 patients without distant metastases $(\mathrm{P}>0.05)$.

DTC who had no distant metastasis disease. Given the results, we suggested radioiodine would not be applied for metastasis-free patients with locally advanced DTC postoperatively.

\section{Acknowledgments}

Funding: This study was funded by Jiangsu Provincial key research development program (BE2016796), the Six Talent Peaks Project (2016-WSW-022), the project of Nanjing Science and Technology Commission (201611006), the China Postdoctoral Science Foundation (2017M621676).

\section{Footnote}

Reporting Checklist: The authors have completed the STROBE reporting checklist. Available at http://dx.doi. org/10.21037/atm-18-1301

Data Sharing Statement: Available at http://dx.doi. org/10.21037/atm-18-1301

Conflicts of Interest: All authors have completed the ICMJE uniform disclosure form (available at http://dx.doi. org/10.21037/atm-18-1301). The authors have no conflicts of interest to declare.
Ethical Statement: The authors are accountable for all aspects of the work in ensuring that questions related to the accuracy or integrity of any part of the work are appropriately investigated and resolved. The trial was conducted in accordance with the Declaration of Helsinki (as revised in 2013). This study was approved by the Ethical Committee of Nanjing Medical University Affiliated Cancer Hospital (No. 2020032). Written informed consent was provided by all of the study participants.

Open Access Statement: This is an Open Access article distributed in accordance with the Creative Commons Attribution-NonCommercial-NoDerivs 4.0 International License (CC BY-NC-ND 4.0), which permits the noncommercial replication and distribution of the article with the strict proviso that no changes or edits are made and the original work is properly cited (including links to both the formal publication through the relevant DOI and the license). See: https://creativecommons.org/licenses/by-nc-nd/4.0/.

\section{References}

1. Shaha AR. Implications of prognostic factors and risk groups in the management of differentiated thyroid cancer. Laryngoscope 2004;114:393-402.

2. Haugen BR, Alexander EK, Bible KC, et al. 2015 American 
Thyroid Association Management Guidelines for Adult Patients with Thyroid Nodules and Differentiated Thyroid Cancer: The American Thyroid Association Guidelines Task Force on Thyroid Nodules and Differentiated Thyroid Cancer. Thyroid 2016;26:1-133.

3. Nakao K, Kurozumi K, Fukushima S, et al. Merits and demerits of operative procedure to the trachea in patients with differentiated thyroid cancer. World J Surg 2001;25:723-7.

4. McCaffrey TV, Bergstralh EJ, Hay ID. Locally invasive papillary thyroid carcinoma: 1940-1990. Head Neck 1994;16:165-72.

5. Bayles SW, Kingdom TT, Carlson GW. Management of thyroid carcinoma invading the aerodigestive tract. Laryngoscope 1998;108:1402-7.

6. Honings J, Stephen AE, Marres HA, et al. The management of thyroid carcinoma invading the larynx or trachea. Laryngoscope 2010;120:682-9.

7. Robbins RJ, Schlumberger MJ. The evolving role of (131)

Cite this article as: Yao Y, Cheng S, Xu X, Chen X, Chen W, Qian Y, Zhang Y. Prognostic factors and the effect of radioiodine on patients with locally advanced differentiated thyroid cancer. Ann Transl Med 2020;8(15):928. doi: 10.21037/atm-18-1301
I for the treatment of differentiated thyroid carcinoma. J Nucl Med 2005;46 Suppl 1:28S-37S.

8. Wong JB, Kaplan MM, Meyer KB, et al. Ablative radioactive iodine therapy for apparently localized thyroid carcinoma. A decision analytic perspective. Endocrinol Metab Clin North Am 1990;19:741-60.

9. DeGroot LJ, Kaplan EL, McCormick M, et al. Natural history, treatment, and course of papillary thyroid carcinoma. J Clin Endocrinol Metab 1990;71:414-24.

10. Mazzaferri EL, Jhiang SM. Long-term impact of initial surgical and medical therapy on papillary and follicular thyroid cancer. Am J Med 1994;97:418-28.

11. Taylor T, Specker B, Robbins J, et al. Outcome after treatment of high-risk papillary and non-Hurthlecell follicular thyroid carcinoma. Ann Intern Med 1998;129:622-7.

12. de Vathaire F. The carcinogenic effects of radioiodine therapy for thyroid carcinoma. Nat Clin Pract Endocrinol Metab 2008;4:180-1. 